\title{
De Arrob@, Lenguaje Inclusivo y Profesiones "Femeninas" en los Medios de Comunicación
}

\author{
On Arrob@, Inclusive Language And «Female» Occupations In The Media
}

\author{
Pilar Úcar Ventura ${ }^{1}$
}

\section{RESUMEN}

En el presente artículo se pretende revisar y analizar el estado de la cuestión del signo de la @ en los medios de comunicación, así como criticar su uso y su proyección en el futuro, dado que empieza a ser sustituida por la $X$, siempre en relación con el lenguaje inclusivo que aparece en los titulares mediáticos y en concreto con el que se refiere a la denominación de las profesiones ejercidas por las mujeres en la actualidad. Se trata de estudiar la rentabilidad y visibilidad de la feminización terminológica — no solo real y social- en la prensa escrita para el logro de una comunicación exacta y adecuada a los nuevos tiempos.

Palabras clave: arroba, lenguaje inclusivo, profesiones, medios de comunicación

\section{Abstract}

The present article means to review and analyze the estate of the question about the @ symbol in mass media. To criticize its use and projection on the future, given that it is starting to be substituted by the letter $X$, always in relation to inclusive language which appears in media headlines and specifically with that which refers to the denomination of professions carried out by women nowadays. The purpose is to study the effectiveness and visibility of the terminological feminization -not just real and social- in written press for the achievement of an exact and adequate communication in this new era.

Key words: at, inclusive language, professions, media communication

ablar y escribir, todo un arte. Y más, hacerlo bien: con corrección y propiedad. Todo un arte de la seducción, pues se trata de llegar a la conciencia del oyente y del lector. Quienes nos dedicamos

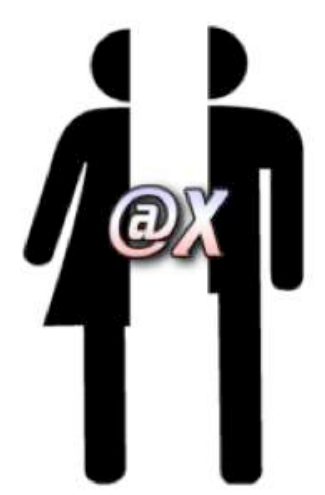

a la comunicación escrita, lo sabemos. Pero vamos por partes: la captatio benevolentiae, tiene su miga: Aristóteles y Platón, Varrón con su gramática y Nebrija después, Port Royal, el estructuralismo y el generativismo, Saussure y Chomsky, han dedicado páginas a dilucidar la función del lenguaje — social— sin ninguna duda, su intencionalidad y su finalidad, por eso, queremos centrarnos en el lenguaje mediático, el que emplean los medios de comunicación y, en concreto, la prensa escrita a la hora de expresar la inclusión o no de términos femeninos referidos a las profesiones ejercidas por las mujeres, entre otros aspectos. Nos vemos en la necesidad de revisar y analizar

1 Doctora en Ciencias de la Educación, Licenciada en Filología Hispánica, Diplomada en Filología Francesa. Profesora de Lengua y Literatura. Departamento de Traducción e Interpretación y Comunicación Multilingüe Facultad de Ciencias Humanas y Sociales (CIHS,) Universidad Pontificia Comillas, Madrid, España. 
el tipo de relato y de discurso que enhebran los periódicos: ha de ser argumentativo, o sea, que adopte decisiones para ofrecer al público, de una manera cohesionada y coherente, el dominio del acto y del efecto así como de la elocuencia. Apoyamos la definición de la Real Academia Española: el arte de bien decir, de dar al lenguaje escrito o hablado eficacia para deleitar, persuadir o conmover. Ahora bien, para llegar a ese momento de emoción y de empatía hay un largo trabajo: conviene diseñar una urdimbre que dé peso y solidez al texto, a la noticia: desde la sombra se trabaja la inventio, la dispositio y la elocutio hasta llegar a la actio: se pone en marcha la maquinaria que elabora y selecciona ideas, materiales con una línea determinada. Empecemos.

"Buenas tardes a todas y a algún todo...": fueron las palabras que se escucharon por parte de una política en nuestro país, hace algún tiempo y no pasaron desapercibidas para la concurrencia reunida. Deja de resultar chocante la repercusión que tuvieron, dados estos tiempos en los que se vigila con lentes de aumento la corrección e incorrección lingüísticas en todo momento por los medios de comunicación. Podemos suponer que este saludo quizá se debiera al deseo de agradar a todos los que formaban parte de su auditorio, aunque "ese algún todo" masculino estuviera mínimamente representado en la sala... Y nos podemos plantear a continuación qué pensarían nuestros lectores si empezáramos alguna de las conferencias que dictamos o de los artículos que escribimos de la siguiente manera: "bienvenidos y bienvenidas, queridos alumnos y queridas alumnas, estimados invitados y estimadas invitadas, apreciados profesores y apreciadas profesoras, en definitiva, amigos y amigas...". O tal vez debería haber empezado así: bienvenid@s querid@salumn@s..., con la dificultad de la lectura del signo @(1) sin proyección de transparencia o diapositiva que aclarara de qué se trata. Conviene pararse y reflexionar qué está pasando en la sociedad, en nuestra realidad de la que se hacen eco los medios de comunicación. Venimos observando, pues, que el fenómeno de la arroba no deja indiferente a casi nadie y dicha polémica es recogida por los medios de comunicación; por ello, nuestros informadores han de saber la responsabilidad que adquieren con sus publicaciones, el impacto mediático que alcanzan sus titulares, pues llegan a constituirse en modelos y referentes seguidos por una gran mayoría, como su propio nombre lo indica: mass media, todo un auténtico espectáculo de masas.

El rigor en la información no constituye una recomendación banal, igual que la claridad de ideas. Si se domina la materia y el texto está bien redactado, habla de la profesionalidad del periodista y favorece la comunicación y la correcta interpretación de su contenido entre emisor y receptor. Pongamos algunos ejemplos:

$\mathrm{Si}$ escuchamos o leemos: "ciudadanos, ciudadanas, las vascas y los vascos, los niños y las niñas, los parados y las paradas"...", seguramente que se haría interminable la noticia y para los telespectadores resultaría un sacrifico $y$ un esfuerzo en vano, pues ya sabemos que el tiempo es oro y más en esta sociedad de la comunicación en la que la rapidez prima a la hora de transmitir contenidos que lleguen a un mayor número de personas en un radio lo más amplio posible.

1 Pero analicemos con detenimiento algunas de las acepciones de la arroba que aparecen registradas en el diccionario de la RAE y en Corominas.

1. Del árabe hispánico arrúb, y este del árabe clásico rub, cuarta parte.

2. Símbolo que se utilizaba para representar la unidad de masa con un peso equivalente a $11,502 \mathrm{~kg}$.

3. Corominas, en su Diccionario etimológico, la documenta en 1219: peso equivalente a la cuarta parte de un quintal.

Acta Herediana vol. 62, N 1, enero 2019 - junio 2019 
Para resolver, pues, el problema de la tediosa repetición, del consumo de tiempo innecesario, se ha introducido el símbolo de la arroba @(2), utilizada a modo de recurso gráfico para integrar en una sola palabra las formas masculina y femenina del sustantivo, ya que por su aspecto ese símbolo incluye, en apariencia, las vocales $a$ y $o$.

Con ello se pretendía evitar las engorrosas repeticiones a que da lugar la reciente e innecesaria costumbre de hacer siempre explícita la alusión a los dos sexos (los vecinos y las vecinas, los viajeros y las viajeras, etc.). Sigamos con algún titular que se puede leer en la prensa española y en la publicidad: “Navegar segur@ por internet", “Protegiendo a los niñ@s".

Ahora bien, debe tenerse en cuenta que la arroba no es un signo lingüístico y, por ello, su uso resulta inadmisible desde el punto de vista normativo; a esto se añade la imposibilidad de aplicar esta fórmula integradora en muchas situaciones sin dar lugar a graves inconsistencias, como ocurre en "Día del niñ@", donde la contracción "del" sólo es válida para el masculino niño.

La amplia difusión de las tecnologías de la información y de internet nos ha hecho familiarizarnos con el uso de la arroba y de esta forma comienza a aparecer en textos del castellano como una grafía más. En cuanto a su utilización dentro de una propuesta de lenguaje no sexista, se utiliza generalmente en sustitución de la terminación "-os" del masculino usado como genérico con la intención de introducir la doble marca de

2 Los usuarios de informática emplean la @ con el sentido de 'en' (at en inglés) en las direcciones de correo electrónico; a comienzo y mitad del siglo XX, fue un símbolo usado en los libros de texto como representación del área, especialmente en los manuales de matemática e ingeniería. género, masculino $\mathrm{y}$ femenino, La idea consiste en dar una respuesta no sexista como referencia a ambos sexos, pues el uso del género masculino resulta discriminatorio.

Presentamos, a continuación, algunos ejemplos a continuación en los que el género masculino se usa como el no marcado, tal y como propone la Academia de la Lengua: el Príncipe a los afectados por el volcán: "No estáis solos" y el siguiente: "Las aulas para alumnos con discapacidad están saturadas". Pero parece ser que, según los más puristas y que además propugnan el uso de la arroba, en el primer ejemplo, las afectadas por el volcán quedarían excluidas, y en el segundo las aulas sólo van destinadas a los alumnos, chicos, y dejan fuera, por lo tanto, excluyen de nuevo, a las alumnas.

Sigamos con algunos ejemplos más que podemos leer en los periódicos: "Los eslovacos estaos de luto por España". Resulta de todo punto obvio que no sólo los hombres eslovacos sienten pena por España ante una tragedia y que en este otro ejemplo: “Los 22700 pasajeros afectados", el avión también iría ocupado por personal femenino, sin lugar a dudas. Y, por último, en la comunidad de Madrid son mujeres y hombres los que conducen, de ahí que el abandono como reza el titular se hubiera producido por unos y por otras aunque no se aporten datos de su proporción: "Casi 9000 madrileños han dejado su coche abandonado en el taller".

Analicemos a continuación qué supondría el uso de la arroba en casos como los que proponemos: "El ABC de los niñ@s". De esta manera, vemos1@s niñ@s como alternativa a "los/as niños/as" o simplemente a "los niños." $\mathrm{Si}$ bien puede resultar un recurso alternativo en un cierto tipo de mensajes o de textos con un contexto no muy formal, no se recomienda su 
utilización, pues a los problemas que plantea la barra (/) se une el que no se pueda reproducir oralmente y el que no se trate de una grafía de la lengua castellana.

Parece, por tanto, que la cuestión del lenguaje inclusivo y el lenguaje de género es un debate que tienelugar en la lengua española desdehace varios años. Los primeros estudios relevantes comienzan en la década de los setenta (Cabeza \& Rodríguez, 2018). Prácticamente, todos los autores comparten la misma opinión de que el lenguaje en sí mismo no puede ser sexista. En un artículo de 2007, Joan Busquet afirma que el sexismo «no reside en el lenguaje, sino en la sociedad: las discriminaciones lingüísticas no son más que el reflejo de las desigualdades sociales» (Busquet, 2007). Está claro que partimos del principio de que la sociedad española es sexista $y$, por lo tanto, la manera de utilizar el lenguaje también lo es. Y aquí está el debate: ¿el lenguaje evolucionará y cambiará solo una vez cambie la sociedad o es necesario forzar el lenguaje para cambiar el pensamiento de las personas y de esa manera influenciar el cambio de la sociedad? Parece obvio que modificando únicamente una sola de las variables, el cambio no va a ser muy profundo. Muchos autores (Ignacio Bosque, Pedro Álvarez de Miranda, Rosa Montero, Joan Busquet) están a favor y argumentan la primera posibilidad: cambiar la sociedad y dejar que el lenguaje avance. Y aun así, como explica Álvarez de Miranda: los aspectos del lenguaje «que afectan a la constitución interna del sistema, a su núcleo duro, no cambiarán, porque no pueden hacerlo sin que el sistema deje de funcionar» (Álvarez de Miranda, 2012). En su informe de 2012, la RAE afirma que, aunque «en ciertos fenómenos gramaticales puede encontrarse un sustrato social, lo más probable es que su reflejo sea ya opaco y que sus consecuencias en la conciencia lingüística de los hablantes sean nulas» (Bosque, 2012).
Esta afirmación resulta completamente contraria a la idea de la representación social y la lingüística cognitiva. Bosque afirma que las personas no utilizan el lenguaje de modo sexista intencionadamente, lo cual sigue siendo discutible, pero no contempla el lado del receptor, la posibilidad de que es posible que haya mujeres que no se sienten representadas por determinados términos debido a ese "sustrato social". La mayor parte de académicos que respaldan dicha idea afirman que no es necesaria la inclusión de términos feminizados porque el lenguaje español precisa de acompañar los sustantivos con determinantes, y estos son los que aclaran si el término se aplica a una persona de género femenino o masculino.

Por otro lado, el sector que pide y promueve el cambio del uso del lenguaje, que podríamos considerar la facción "feminista" de la sociedad y las instituciones públicas, utiliza la reflexión del filósofo y lingüista George Steiner de que "lo que no se nombra no existe". Con esto defienden que cuando una persona elige utilizar un término masculino para referirse a una mujer le está quitando visibilidad tanto a ella como al resto de mujeres que ejercen esa profesión (Lledó, 2002). Es cierto que, en la mayoría de los casos, según ha cambiado la situación social de la mujer se han ido feminizando los términos de las profesiones a las que iban accediendo, aunque siempre a posteriori. $\mathrm{Y}$ es normal que, como cualquier institución del mundo, el cambio y la modernización llegue a la RAE con retraso respecto a la situación social del momento, especialmente si tenemos en cuenta que para que la RAE reconozca una palabra para introducirla en el diccionario tiene que considerar que está suficientemente arraigada en la sociedad. Sin embargo, en muchos casos nos encontramos con que la sociedad y la institución avanzan, pero de manera desigual. 
De todos modos, no podemos obviar el hecho de que cuenta con usuarios que lo defienden a ultranza, pero con argumentacionesideológicas ajenas y distantes del razonamiento lingüístico. De esta manera se evitan las distorsiones conceptuales, la polisemia lingüística y la ambigüedad, en definitiva, la falsedad y casi el engaño ${ }^{(3)}$.

Ahora bien, tal y como lo dice la Real Academia de la Lengua, la @ es un símbolo no alfabetizable, sin cuerpo fonológico, que se coloca entre usuario y servidor en el correo electrónico; además y en relación con lo que venimos hablando respecto del género gramatical, el género no marcado es el masculino, por lo tanto, el que engloba a masculino y femenino.

Pero avancemos un poco más en lo que consideramos rizar el rizo o dar una vuelta de tuerca al tema: el uso que en la actualidad se le está dando a la equis $(\mathrm{X})$ en muchos de los mensajes publicitarios que vemos diariamente; se trata de ejemplos en los que la @ se sustituye por la $X$. En el campo de las matemáticas es la incógnita, y cabría preguntarse si muchos de los mensajes han quedado reducidos a una incógnita que hay que descubrir y despejar para dar con la solución a lasecuaciones de diferentes grados, es decir, acertar con la descodificación de los mensajes muchas veces crípticos que encontramos; recordemos que hace unas décadas se acuñó la expresión Generación $X$ que hacía referencia a la generación de jóvenes de los ochenta, marcada por la apatía, incluso se llegó a tildar de generación perdida ${ }^{(4)}$.

3 Jeffrey, S. y Úcar, P., "Del concepto a la competencia: la síntesis para la interconexión de la lengua A y la lengua B", Actas del XVI Congreso Internacional de La Asociación de Lingüística y Filología de la América Latina, Alcalá de Henares, 2012, p. 2925.

4 Úcar, P., La lectura de teatro contemporáneo en los procesos de enseñanza-aprendizaje de español como segunda lengua en estudiantes universitarios, Madrid, UPCO, 2006.
Podemos pensar que hoy en día vivimos en sociedades ampliamente informatizadas, sociedades donde prima lo audiovisual, donde una imagen vale más que mil palabras, y quizá como apuntan ciertas voces sean éstas algunas de las razones que favorecen la proliferación de símbolos como la arroba identificativos de señas y estandartes de asociaciones juveniles, partidos políticos, etc.

Junto al machismo, que subordina todo al ser macho, han creado el hembrismo (feminazismo en boca de Pérez-Reverte ${ }^{(5)}$ ), como se advierte en el siguiente titular: "Las señoras miembros de Montoro".

Vemos, por tanto, que se está desarrollando un pseudomasculino plural en contra del principio de las máximas de la pragmática que postula Grice ${ }^{(6)}$, al afirmar que todo hablante para garantizar su comunicación ha de ser "ahorrador" y ha de usar el principio de la economía lingüística siempre que transmita lo que es informativamente necesario; por ejemplo, en nuestro discurso oral, no somos del todo conscientes de cuántas veces emitimos expresiones del tipo: "al grano, sin rodeos..." Pues bien, para evitar la reiteración y la pedantería aparece el uso de la arroba que por su grafía, ya hemos visto, se cree que coinciden el género masculino y femenino con la $o$ y la $a$, respectivamente. Pero no podemos perder de vista el principio ineludible de que el uso de la lengua es un derecho, y su correcta difusión, una obligación.

5 Pérez Reverte, A., "Pérez Reverte caldea el motín de las "feminazis" contra la RAE. http://www.elsemanaldigital. $\mathrm{com} /$ perez-reverte-caldea-el-motin-de-las-feminazis-contrala-aberracion-de-la-rae-120147.htm

6 Romana, M. L., y Úcar, P., "Analysis of mistakes in translation learning: The notion of 'competential loss'", Iberian Studies on Translation and Interpreting, Berna: Peter Lang (71 - 90), 2012, p. 83. 
Entre las principales propuestas encontramos las siguientes que pueden resultar válidas en la mayoría de contextos, por ejemplo, para la designación del término "hombre" se prefiere el de "humanidad", "niños" podría ser reemplazado por "gente", en lugar de "los trabajadores", utilizar "el personal", "coordinación" mejor que "coordinador" o , “jefatura" para "jefe" y "quien supervise" para evitar "supervisor"... podríamos continuar con otros: "personas con discapacidad" para referirse a "discapacitados", "personal secretarial" y no "secretarios" o "secretarias" (sobre esta cuestión, volveremos luego).

En palabras del director de la Academia Boliviana de la Lengua, Raúl Rivadeneira: “El género es una propiedad de los nombres y de los pronombres que tiene carácter inherente y produce efectos en la concordancia con los determinantes, los adjetivos... y que no siempre está relacionado con el sexo biológico. Las personas no tenemos género, tenemos $\operatorname{sexo}^{\prime \prime(7)}$.

Para algunos, el mundo se reduce a sexo, según lo que nos quieren hacer leer en los titulares: ese es el lema de esta moderna herejía, en nuestra opinión, pensamos que se confunde género y sexo: una libreta es femenino pero no hembra, un libro es masculino pero no macho. El género común es útil, evita pérdidas de tiempo, sintetiza abarcando ambos géneros y ambos sexos: es más económico decir, cuando traducimos el Evangelio, dejad que los niños se acerquen a mí que decir "los niños y las niñas". Incluso afirmar, con Quintiliano, que al niño se le debe la máxima reverencia", evidentemente a niños y niñas ${ }^{(8)}$.

7 Rivadeneira; R., Manual para la transversalización de género en el Instituto Nacional de Estadística, Guatemala, INE, 2009, p 154.

8 http:/ / icaro-ardiendo.blogspot.com.es/2010/04/saludostodas-y-todos.html\#! / 2010/04/ saludos-todas-y-todos.html (Fecha de consulta: 1 de marzo de 2013.)
Como se ha anticipado líneas arriba, pretendemos tratar también la evolución del lenguaje en la feminización de términos, en cuáles son los puntos de vista actuales de académicos, filólogos y lingüistas y cómo se justifican o se aplican sus argumentos, y revisar la tendencia actual de utilizar términos en femenino de nombres de profesiones, cargos o títulos. Esta tendencia, que empieza a emerger en España pero que ya está bastante extendida en otros países hispanohablantes, para muchos es motivo de sorpresa o lo consideran un error o un episodio cómico. Los ejemplos más actuales son la primera vez que una diputada utilizó el término miembras, en lugar de miembros, para referirse a las mujeres que participan en el Congreso en 2008, que desde entonces ha sido repetido por otras figuras públicas en más ocasiones, o cuando una diputada utilizó la palabra portavoza, en lugar de portavoz, durante una intervención en el pleno del Congreso de los Diputados. Pero otros términos, como pilota o cargos del ejército como generala que la población no sabe si deben usar o cómo debe utilizarlos. El análisis del uso del masculino y el femenino para referirse a profesiones es interesante porque refleja el ideario de la sociedad a la hora de referirse a las mismas, es "una radiografía del estado de la cuestión" "refleja la relación entre la jerarquía social y la subordinación lingüística" (Lledó, 2002).

Por ello, seguimos encontrando una importante facción que reivindica el masculino como género no marcado. Es decir, que cuando se busca referirse a un grupo compuesto por mujeres y varones se utiliza el género masculino. Esta es una de las herramientas para facilitar la comunicación y asegurar la economía del lenguaje, pero también se discute por invisibilizar la presencia de la mujer. La consecuencia más inmediata de este debate 
es la búsqueda de un lenguaje inclusivo y la cuestión del desdoblamiento de términos.

Según ha evolucionado la historia y las mujeres han accedido a puestos y sectores a los que antes no podían, la lengua ha evolucionado y ha adaptado los términos para reflejar esta inclusión. Especialmente en castellano existe la tendencia y el recurso de feminizar los sustantivos añadiendo el fonema / a / . Aunque la evolución sea lenta, el castellano no tiene problema en crear neologismos (Lledó, 2002).

En el Diccionario panhispánico de dudas, la Real Academia Española ofrece una serie de normas para formación del femenino en profesiones, cargos y títulos, pero las normas son escuetas, ofrecen ejemplos y excepciones concretas que dificultan y confunden en su aplicación, lo que las convierte, más que en una herramienta para la feminización de términos, en una gramática descriptiva y enunciativa de los términos que ya existen.

Por ejemplo, en los casos en los que los sustantivos terminen en -ente, -anta, la RAE explica que funcionarán en su mayoría como sustantivos comunes, véase estudiante, y no estudianta. Aun así, nombra algunas excepciones generalizadas aceptadas por la academia como cliente/clienta o presidente / presidenta. Además, la RAE se ha pronunciado en cuanto al desdoble de género en textos escritos, pero no hay ninguna publicación o declaración acerca de los últimos términos en femenino que se han comenzado a utilizar a nivel popular, en algunos casos político. Les contaré que la nieta de tres años de una amiga mía me dijo que quería ser pilota, sin titubeos En su cabecita debió pensar: "Si un hombre que maneja una nave es piloto; yo, pilota". Ahora bien, ¿qué pasaría si preguntáramos a nuestras jóvenes estudiantes qué desean ser en un futuro? Quizá alguna contestara que piloto, pero me atrevo a asegurar que no en femenino.
Al pronunciar "pilota" se arriesgaba a la hilaridad del resto, al gesto raro: ¡qué mal suena! Me consta que muchas de las profesionales en ejercicio pertenecientes a sectores como la jurisprudencia, la ciencia y la técnica se definen como fiscal, ingeniero, físico, arquitecto, juez. Sí es cierto que leemos en algunos titulares "jueza", pero no deja de advertirse cierta renuencia a hacerlo de manera fluida. Parece, pues, que la tendencia no va en el sentido de "pilota". Y eso que la Fundéu acepta el término, mientras que la RAE prefiere la piloto.

Sabemos por la normativa académica que el género gramatical no marcado es el masculino: "los padres" engloba a padres y madres "los estudiantes" a alumnos y alumnas que asisten a nuestras aulas; ahora bien, leemos que la RAE, prefiere "el rey y la reina". ¿Toda una declaración de intenciones? Y desde alguna comunidad se publica un documento que aconseja a sus funcionarios el término de "criaturas" y no el de "el niño y la niña". ¿Estamos asistiendo a una feminización del lenguaje? Por lo que venimos diciendo hasta ahora no es así.

Reconocemos, no obstante, que algo está pasando: la realidad cambia, sufre modificaciones constantes que en algunas ocasiones recoge el idioma. Y eso está muy bien: la inquietud por la lengua, por su expresión y la comunicación.

Ahora bien, necesitamos tiempo, adaptación, acomodo y reflexión. Conviene profundizar en la intención del mensaje: no se puede vender humo. La lengua ha de estar anclada a la realidad y la realidad se ha de ver reflejada en la lengua. Acompasar el ritmo de una y otra cuesta.

Imaginemos nuestra asistencia a una conferencia, por ejemplo, en la que su protagonista nos saluda así: "Bienvenidos, 
bienvenidas, buenas tardes a todos y todas, amigos y amigas, queridos y queridas asistentes y asistentas..." y así ad infinitum. Sospecho que el auditorio se incomodaría en sus sillas y se preguntaría: “iHasta cuándo?”. Quizá a alguno se le ocurra acudir en auxilio de la @ o de la X o de la e. Claro que si además nos piden la redacción de un artículo, la duda es acuciante hasta cierto punto: somos conocedores de la importancia del cómputo de las palabras y de la extensión de las líneas para una publicación. Quizá no resulte tan negativo el criterio de la economía (espacio-temporal) para seguir empleando el género masculino (no marcado gramaticalmente).

Avancemos un poco más en nuestras reflexiones: conforme la mujer se incorpora a nuevos trabajos desempeñados tradicionalmente por hombres, el idioma ha de incorporar esas nuevas palabras que las definen: sumillera, crupiera, alfereza, caba... Fruncimos el ceño, seguro, y somos capaces hasta de pronunciar en alto a la vez que leemos estas líneas para escucharnos. Lo ocasional y lo esporádico —nunca marginal- deben dar paso a lo habitual; hay que atender las nuevas corrientes sociales, escuchar y prestar oídos a lo distinto. No desterrarlo de buenas a primeras. A vueltas con el femenino, quienes nos dedicamos a la enseñanza del español a extranjeros, temblamos en la lección dedicada al vocabulario de animales. A todos nos vienen imágenes de tiburón, ballena, zorro, vaca, perro. ¡Cuántas connotaciones negativas!, por supuesto, siempre que se dirigen a la mujer. Aquí lo dejo. Igual que hoy con alguna "tipa", "individua" o "elementa", el escandaloso "miembra" de hace años nos parece una ingenuidad.

En efecto: hay que apoyar, sin cortapisas, la diversidad, la visualización, la empatía... con sentido común y sin llegar al absurdo ni a lo rocambolesco. No podemos permitir que la carcasa confunda, destruya y distorsione el mensaje, como el lema que algunos cargos públicos lucen: "Si no puedes convencerlos, confúndelos". No somos ni ignorantos ni ignorantas.

La palabra es puente entre personas: la palabra acerca, acompaña, atrae y seduce.

\section{Conclusión}

"El buen hablar está en los discretos cortesanos", decía Cervantes, y lo decía cuando la gente depositaba en la gramática su confianza absoluta.

El adjetivo discretos aplicado a cortesanos alude en la actualidad a 'ciudadanos', es decir, nos incluye a todos. Cervantes concita a generaciones de hombres y mujeres, comunes o sobresalientes, que comparten el riesgo y el placer de usar la lengua, nuestro idioma, patrimonio de todos. Quien bien habla y bien escribe destaca porque sabe discernir, distinguir y diferenciar. Hablar para transmitir ideas, sentimientos, opiniones... Escribir para plasmar y fijar convicciones, aciertos y desencuentros. Todo ello en el marco del acercamiento al otro con la mano tendida para lograr una diversidad global gracias a la palabra proferida y a la escrita. Comunicamos con fe y con ganas desde un optimismo reparador, ofreciendo hospitalidad sin alarmar ni confundir. Escribir y hablar bien son valores que cotizan al alza en nuestros días y recorrer los entresijos del lenguaje oral y escrito permite una proximidad entre pueblos y naciones, sin ofensas ni vituperios con sinceridad afectiva. Hablar bien es fruto de un cerebro nutrido de curiosidad, interés y reflexión, de una preparación intelectual y una voluntad de conocer al otro y de darse a conocer a los demás. Escribir bien es el proceso por el que 
pensamientos, deseos e ilusiones perviven en el tiempo, al margen de caducidades perentorias. Sabemos que las lenguas evolucionan, pero evolucionan con el uso popular, no con imposiciones políticas de arriba hacia abajo. Y si al principio fue el verbo y el lenguaje es lo más social que tenemos, deberemos estar atentos y ser vigías del maltrato y de la persecución a que se ve sometido nuestro idioma: por su buen uso, me gustaría animar a su corrección y dado que nuestra lengua constituye un modo de sentir el universo, debemos humanizarlo. Reivindicamos la escritura culta, no erudita siempre, pero sí intelectual en los medios de comunicación, en los periódicos, en la televisión...; la precisión iguala la realidad y refleja una mentalidad ordenada que no aburrida.

Desde las aulas tenemos que adquirir no sólo la obligación sino el férreo compromiso de preparar a nuestros alumnos en el sentido igualitario de la justicia y de las oportunidades para todos ellos, sean mujeres o varones, y el lenguaje ha de ser un elemento muy importante que contribuya a que esa realidad se lleve a cabo; ellos son los auténticos guardianes del patrimonio de la lengua, referentes de otras generaciones que seguirán sus pasos allá donde ejerza cada uno la profesión para la que se ha preparado: traductores, empresarios, profesores, embajadores, poetas, intérpretes... han de permanecer atentos a la arroba, al género, al estilo, a la información, en definitiva, a la comunicación.

\section{REFERENCIAS BibLIOGRÀFICAS}

1. Álvarez De Miranda, P. (7 de marzo de 2012). El género no marcado. El País.

2. Andrés Castellanos, S. "Sexismo y lenguaje". Espéculo. Revista de estudios literarios. Universidad Complutense de Madrid [en línea] http://www.ucm.es/info/especulo/numero17/ sexism2.html (Fecha de consulta: 4 de febrero 2012.)

3. Bosque, I. "La RAE, las palabras y las personas". El País. Obtenido de Fundéu BBA. Noticias del español (5 de diciembre de 2005).

4. Bosque, I. "Sexismo lingüístico y visibilidad de la mujer". Boletín de Información Lingüistica de la Real Academia Española (marzo de 2012).

5. Bosque, I. "La RAE arremete contra las guías de lenguaje no sexista”. http: / / www.rtve.es/noticias/20120304/raecritica-guias-lenguaje-no-sexista-si-se-aplicasen-no-se-podriahablar/504241.shtml. (Fecha de consulta: 1 de marzo de 2013.)

6. Durán, F. "Sorpresas del lenguaje no sexista". Cincodias. com. CincoDías. 12 en. 2011. Web. 13 feb. $2012<$ http:// www.cincodias.com/articulo/opinion/sorpresas-lenguajesexista/20110112cdscdiopi_1/>

7. Gené, M. "La arroba ¿un símbolo no sexista de género?". Fundeu.es. Fundéu BBVA: Fundación del Español Urgente. 17. Dic. 2007. Web. 13. Feb. 2012 <http: / / www.fundeu.es/noticiasarticulos-la-arroba-un-simbolo-no-sexista-de-genero-4131. html >

8. González, L. “¿Es usted sexista (en su lenguaje)?”. Elmundo.es. El Mundo. 5 feb. 2012. Web. 13 feb. $2012<$ http://www. elmundo.es/elmundo/2012/02/03/espana/ 1328274657. html>

9. Jeffrey, S. y Úcar, P. “Del concepto a la competencia: la síntesis para la interconexión de la lengua A y la lengua B", Actas del XVI Congreso Internacional de La Asociación de Lingüística y Filología de la América Latina (Alcalá de Henares, 6-9 de junio de 2011), pp. 2921-2927, Alcalá de Henares, 2012.

10. Lledó Cunill, E. (2002). "Ministras, arrieras y azabacheras". El cajetín de la lengua.

11. Pérez Reverte, A. "Pérez Reverte caldea el motín de las "feminazis" contra la RAE". http://www.elsemanaldigital. $\mathrm{com} /$ perez-reverte-caldea-el-motin-de-las-feminazis-contrala-aberracion-de-la-rae-120147.htm

12. Pire, C. R. El lenguaje y el empleo simultáneo del masculino y el femenino, 2009. Scientific Electronic Library Online <http:// www.scielo.org.ve/pdf/ba/v21n3/art01.pdf $>$ (Fecha de consulta: 4 de febrero 2012.)

13. Rodríguez, G. "Alternativas y soluciones al lenguaje no sexista del Principado de Asturias". Institutoasturianodelamujer.com. Consejería de la Presidencia, Instituto Asturiano de la Mujer. 2011. Web. 13. Feb. $2012<$ http:/ / institutoasturianodelamujer. com / iam/ wp-content/ uploads / 2011 / 04 / Alternativas-ysoluciones-no-sexistas-al-lenguaje-administrativo-delPrincipado-de-Asturias.pdf $>$

14. Romana, M. L., y Úcar, P. “Analysis of mistakes in translation learning: The notion of 'competential loss'", Iberian Studies on Translation and Interpreting, Berna: Peter Lang. (71-90).

15. Úcar, P. La lectura de teatro contemporáneo en los procesos de enseñanza-aprendizaje de español como segunda lengua en estudiantes universitarios, Madrid, UPCO, 2006.

16. Vicenty, C. "Socialización, lenguaje y educación". Revista de Antropología Experimental, N. ${ }^{\circ} 3$ [en línea] http: / / www.ujaen. es/huesped/rae/articulos2003/vicenty2003.pdf (Fecha de consulta: 4 de febrero 2012.)

17. Wagner, C. "Lenguaje y género". Documentos Lingüisticos y Literarios 26-27: 41-44 www.humanidades.uach.cl/ documentos_linguisticos / document.php?id=58 (Fecha de consulta: 4 de febrero 2012.) 